\title{
O REPENSAR SOBRE AS DIFICULDADES E INQUIETUDES EXISTENTES NA EDUCAÇÃO ESPECIAL
}

\author{
THE RETHINKING OF THE DIFFICULTIES AND CONCERNS IN SPECIAL EDU- \\ CATION \\ EL REPLANTEAMIENTO DE LAS DIFICULTADES Y PREOCUPACIONES EN MA- \\ TERIA DE EDUCACIÓN ESPECIAL
}

\author{
Cassandra Catarina Gonçalves Mineiro \\ Doutora em Ciências da Educação pela Universidade de Trás-os-Montes e Alto Douro/Portugal. \\ Pesquisadora do Núcleo de Sociedade Inclusiva - NUSI, Departamento de Educação - CCH/UNIMONTES. \\ cassandramineiro@hotmail.com
}

\begin{abstract}
RESUMO: Após introdução da inclusão nas escolas, o conhecimento produzido tem sido insuficiente para a definição dos caminhos psicopedagógicos voltados à escolarização de alunos com necessidades educacionais especiais - NEEs. Isso vem acontecendo, em parte, porque não foram articulados os estudos com a realidade, sendo que autores da maioria desses estudos apresentaram resultados com produções reiterativas e com pouca mudança no que é proposto. O objetivo deste trabalho foi direcionado a conhecer sobre a realidade enfrentada pelos professores das salas de recursos multifuncionais (SRM). Esse estudo envolveu as experiências de professoras da Educação Básica, em pesquisa realizada pelos professores da Universidade Estadual de Montes Claros - UNIMONTES, evidenciando atuação dessas professoras das SRM nas escolas do município de Montes Claros - MG. Como embasamento teórico foram utilizados Decretos e Portarias da Educação Especial, com enfoque nos autores e trabalhos realizados nessa área. A metodologia abrangeu a pesquisa colaborativa, mediante depoimentos das professoras direcionados pelas questões propostas pelo Observatório Nacional de Educação Especial, o que permitiu análise da forma como ocorre a inclusão escolar. Desse modo, a dinâmica na organização de grupos coletivos foi a pesquisa em grupos focais, mostrando a realidade das escolas pesquisadas e quais propostas viáveis a um melhor atendimento às crianças com NEEs. Como resultado, a pesquisa favoreceu o reconhecimento em enfrentar dificuldades; a necessidade de parceria com a professora da sala regular e capacitação desta na Educação Inclusiva; o Plano de Atendimento Educacional Especializado (PAEE), contribuindo essas práticas na melhoria da inclusão escolar direcionada aos alunos da educação especial.
\end{abstract}

PALAVRAS-CHAVE: PALABRAS CLAVE: Educação especial. Realidade das escolas. Atendimento às crianças.

ABSTRACT: After introduction of inclusion in schools, the knowledge produced is insufficient to define the paths psychopedagogic focused on education of pupils with special educational needs - SEN. This is happening in part because studies with reality were not articulated, and authors of most of these studies showed results with reiterative productions with little change in what is proposed. This study was aimed to know about the reality faced by teachers of multi-functional resources (SRM). This study involved the experiences of teachers of basic education, in research conducted by teachers of the State University of Montes Claros - UNIMONTES, showing work of these teachers of SRM in schools in the municipality of Montes Claros - MG. As theoretical basis were used Decrees and Edicts of Special Education, focusing on authors and works carried out in this area. The methodology included the collaborative research by testimony from teachers targeted by the questions proposed by the National Centre for Special Education, which allowed analysis of how is school inclusion. Thus, the dynamics in the organization of collective groups was the research focus groups, showing the reality of the surveyed schools and what feasible proposals to better care for children with SEN. As a result, the survey favored the recognition in facing difficulties; the need for partnership with the teacher regular room and this training in inclusive education; Plan of Educational Service Specialist (EEAP), contributing these practices, improving school inclusion directed to students of special education.

KEYWORDS: Special education. Reality in schools. Care to children.

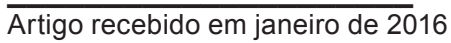

Aprovado em março de 2016 
RESUMEN: Después de la introducción de la inclusión en las escuelas, el conocimiento producido es insuficiente para definir las rutas psicopedagógica centrado en la educación de los alumnos con necesidades educativas especiales - NEEs. Esto está ocurriendo en parte debido a los estudios con la realidad que no se articulan, y los autores de la mayoría de estos estudios mostraron resultados con producciones reiterativos con pocos cambios en lo que se propone. Este estudio tuvo como objetivo conocer la realidad que enfrentan los maestros de recursos multi-funcionales (SRM). Incluyó las experiencias de los profesores de la educación básica, en la investigación llevada a cabo por los profesores de la Universidad Estatal de Montes Claros - UNIMONTES, que muestra el trabajo de estos maestros de SRM en los centros educativos del municipio de Montes Claros - MG. Como base teórica se utilizaron los decretos y edictos de Educación Especial, centrado en autores y obras realizadas en esta área. La metodología incluyó la investigación en colaboración con el testimonio de los profesores afectados por las preguntas propuestas por el Centro Nacional de Educación Especial, lo que permitió el análisis de cómo es la inclusión escolar. Por lo tanto, la dinámica de la organización de los grupos colectivos fueron los grupos de enfoque de investigación, que muestra la realidad de las escuelas encuestadas y qué propuestas viables para una mejor atención a los niños con NEE. Como resultado, la encuesta favoreció el reconocimiento para hacer frente a las dificultades; la necesidad de una asociación con el maestro habitación regular y esta formación en la educación inclusiva; Plan de Educación del especialista de servicio (PAEE), contribuyendo estas prácticas, la mejora de la inclusión escolar dirigido a los estudiantes de educación especial.

PALABRAS CLAVE: Educación Especial. Escuelas realidad. Cuidar a los niños. 


\section{1| INTRODUÇÃO}

Ao realizarmos este trabalho, baseado em pesquisa dos professores pesquisadores da UNIMONTES com 40 professoras da Educação Básica, por meio do projeto "Estudos e Pesquisa das Salas de Recursos Multifuncionais de Montes Claros - MG", vimos traduzir um recorte de enorme abrangência e alcance, por envolver a rede municipal e estadual de ensino do estado de Minas Gerais.

A realização desta pesquisa, no período de 2011 a 2015, se justifica em melhor entendermos a realidade atual do processo de inclusão dos alunos com necessidades educacionais especiais - NEEs nas escolas regulares e o processo de encaminhamento desses alunos às salas de recursos multifuncionais - SRMs. Destaca-se que a dificuldade em analisar os dados da pesquisa e o envolvimento com os sujeitos incidiu em uma soma de esforços em sua concretização. No entanto, pretendemos divulgá-la de forma a contribuirmos na área das ciências humanas, envolvendo psicologia e educação.

É significativo iniciarmos demonstrando os primeiros esforços ao analisarmos o surgimento da Filosofia da Integração, aprovada pela Convenção sobre os Direitos das Pessoas com Deficiência (2007), em que verificamos a premente necessidade de se integrar indivíduos deficientes à sociedade. Atualmente almejamos que esta integração seja inclusão, motivando várias conferências e eventos internacionais, bem como foco de múltiplos estudos e pesquisas, envolvendo a United Nation Educational, Scientific and Cultural Organization (Organização para a Educação, a Ciência e a Cultura das Nações Unidas) - UNESCO, e vários outros órgãos e instituições nacionais e internacionais.

A Organização Mundial da Saúde - OMS (2011), apontou que quase um quinto (1 bilhão) da população global é de indivíduos vivendo com deficiência ou dificuldades significativas. Poucos são os países que dispõem de mecanismos adequados para atender às necessidades educacionais dos indivíduos com deficiência. Várias barreiras são impostas a estes indivíduos, tais como: a discriminação e o preconceito social, a inexistência de adequados cuidados de saúde física e mental, a precariedade de serviços de reabilitação e a inexistência de transportes adaptados, acrescentando a isso a acessibilidade a edifícios e tecnologias de informação e comunicação. Diante desse quadro, os indivíduos deficientes apresentam precariedade na saúde física, fisiológica e intelectual, menor aproveitamento escolar, poucas oportunidades econômicas e, notadamente, elevam a taxa de pobreza, comparada aos indivíduos sem deficiência.

A educação especial vem adquirindo importância crescente nos debates a respeito da política educacional. Assim, educadores e outros profissionais - principalmente ligados à área da psicologia, sociologia e medicina - têm se interessado pelo estudo da criança e jovem com necessidades. Nesses debates, percebemos uma mudança atual de paradigma: estamos tentando sair do paradigma do condicionamento para o paradigma da construção e da interação no processo ensino-aprendizagem dos sujeitos com necessidades educacionais especiais. Percebemos que essa mudança é uma questão de paradigma. Estávamos numa educação que passa da ideia de condicionamento (do não precisa pensar, nem perguntar para que, do fazer) para o paradigma da aprendizagem (do construir, do pertencer constituintemente ao processo), em que o objeto focado é a oportunização do aprender.

Há professoras que buscam compreender o processo e contextualizar-se, e outras que ainda resistem. Diante dessa proposta de mudança, surge a necessidade de se criar as salas de recursos multifuncionais - SRMs, que se destinam a dar o suporte educacional necessário ao aluno deficiente, promovendo dentro da escola um passo decisivo para que a educação inclusiva ocorra. O Programa de Implantação das SRMs tem como objetivo disponibilizar aos sistemas públicos 
de ensino equipamentos, mobiliários, materiais pedagógicos e de acessibilidade para a oferta do atendimento educacional especializado nas escolas públicas de ensino regular (BRASIL, 2010).

As SRMs realizam o atendimento educacional especializado, complementar e/ou suplementar à escolarização dos alunos com NEEs, público alvo desse serviço, em consonância com a demanda registrada no educacenso - INEP ${ }^{1}$. Nesse sentido, o Sistema de Ensino de Montes Claros/ MG vem implementando ações que promovam a expansão do atendimento educacional especializado aos alunos com deficiência, transtornos globais de desenvolvimento e deficiências múltiplas, matriculados nas escolas regulares. Esse atendimento especializado envolve o conhecimento e a aplicação de técnicas de várias áreas, dentre elas, da Psicologia, Saúde e Pedagogia, não somente pela professora das SRMs, como também de outros profissionais da área psicológica e da saúde preventiva. A partir de diagnóstico realizado pelos profissionais da área psicológica e da saúde, os mesmos elaboram laudo para cada criança, oferecido pelas instituições especializadas conveniadas com as escolas, o qual irá direcionar o trabalho das professoras das SRMs, em especial para o atendimento a serviços especializados de apoio: instrutores e intérpretes de Libras para alunos com surdez, auxiliares de docência para alunos com TGD e deficiência múltipla.

Mesmo possuindo formação inicial e anterior, o trabalho nestes ambientes de aprendizagem requer da professora formação continuada. Portanto, por considerarmos a necessidade de tal formação é que objetivamos com o estudo aqui apresentado saber sobre as práticas usadas nas SRMs e realizarmos reflexões sobre as questões do atendimento escolar especializado, visando entendermos sobre essas práticas, conhecendo melhor a realidade das escolas.

Este estudo fez parte da primeira pesquisa realizada pelo Observatório Nacional de Educação Especial - ONEESP, realizada no período de 2011 a 2015, cuja coordenadora nacional foi a Prof ${ }^{a}$ $\mathrm{Dr}^{\mathrm{a}}$ Enicéia Gonçalves Mendes da Universidade Federal de São Carlos. Em Minas Gerais este estudo foi realizado somente na cidade de Montes Claros e teve como coordenadora estadual a Prof $^{a}$ Dr $^{a}$ Cassandra Catarina Gonçalves Mineiro. Portanto, como pesquisadores da UNIMONTES, especificamente do Núcleo de Sociedade Inclusiva - NUSI, propusemo-nos a conduzir este estudo, no qual o delineamento diversificado envolveu estudos locais, com encontro mensal, nos turnos matutino e vespertino, nas salas de aula da universidade, com 40 professores das SRMs das escolas de Montes Claros, utilizando como como base a metodologia da pesquisa colaborativa, com a qual pretendemos coletar dados mediante perguntas disparadoras fornecidas pelo ONEESP. Essa pesquisa colaborativa "com" e não "sobre" os sujeitos envolvidos adotou uma dinâmica a partir da organização de grupos coletivos e de entrevistas com grupos focais, em que foi-nos permita a filmagem, durante todo o período do encontro, e foram respondidas as seguintes perguntas disparadoras: Como é formada a equipe de professores para trabalhar nas SRMs? Quais cursos são necessários e exigidos pelo MEC? E principalmente: como é feito o atendimento educacional especializado voltado para a inclusão escolar? Além dessas, outras mais, cujas respostas foram organizadas e analisadas em forma de relatórios, enviados ao setor responsável da universidade, como também enviados ao ONEESP.

Como atividade complementar, a palestra do professor Carlos Alberto Siqueira Alexandre, psicólogo do NUSI, proporcionou às professoras melhor entendimento de alunos com NEEs, abrangendo o Transtorno do Espectro do Autismo (TEA) e, em especial, Transtorno Desafiador Opositor (TDO).

\footnotetext{
${ }^{1}$ Essas informações [...] servem de referência para a formulação de políticas públicas e execução de programas na área da educação, incluindo os de transferência de recursos públicos como alimentação e transporte escolar, distribuição de livros, implantação de bibliotecas, instalação de energia elétrica, Dinheiro Direto na Escola e Fundo de Manutenção e Desenvolvimento da Educação Básica e de Valorização dos Profissionais da Educação (Fundeb). Disponível em: <http://portal.inep.gov.br/basica-censo>. Acesso em: 24 ago. 2015.
} 
Optamos por um estudo de caráter introdutório, exploratório e problematizador de um tema interdisciplinar, com o objetivo de saber sobre a realidade das práticas mais usadas e que favorecem a inclusão escolar dos alunos com necessidades especiais. A metodologia seguida permitiu que o profissional da educação evidenciasse as suas dificuldades, aspirações e desejos, suscitando debates, em busca de assuntos que interessem especificamente à investigação de problemas relacionados às necessidades educacionais especiais - NEEs, e às dificuldades encontradas nas SRMs locais.

Ao organizarmos esse trabalho visamos o surgimento das SRMs nas escolas de Montes Claros/MG, nas quais pretendemos saber como ocorreu a organização da equipe de docentes a trabalhar nas SRMs, os cursos exigidos e a realidade evidenciada pelas professoras; em seguida a Organização do currículo na educação básica com abrangência no AEE, evidenciando os níveis de inteligência, os ritmos de aprendizagem e as formas como a criança aprende; seguimos com a Organização das Atividades da Educação Básica realizadas nas SRMs, envolvendo mais especificamente os conteúdos de Português e Matemática, para um melhor atendimento na Educação Especial; nos Resultados obtidos e discussão realizada, a criação e unificação de critérios avaliativos do Plano de Atendimento Educacional Especializado (PAEE), o conteúdo e as experiências adquiridas; e no encerramento as Considerações Finais: a criação de diagnóstico preliminar redigido pelas professoras, para que as crianças possam ser encaminhadas às salas de recursos com algum direcionamento pedagógico; participação em capacitação na formação docente; Plano de Atendimento Educacional Especializado (PAEE) a ser usado como critério avaliativo; mais parcerias da escola com a família, considerando estes alguns dos elementos fundamentais para que a educação seja realmente inclusiva.

\section{2| O SURGIMENTO DAS SRMS NAS ESCOLAS DE MONTES CLAROS/MG}

Buscamos por sondar como é formada a equipe de professores a trabalhar nas SRMs e sobre quais cursos de Atendimento Educacional Especializado - AEE as professoras devem possuir para iniciar seu trabalho nessas salas de recursos multifuncionais. Constatamos que a equipe possui curso na área da Educação Inclusiva, para terem direito a assumir a SRMs, sendo esta uma exigência da Secretaria de Educação - MEC.

Investigamos sobre: Como se realiza o AEE nas escolas?, obtendo das professoras das SRMs as seguintes afirmações:

a) O município de Montes Claros encontra-se bem, em relação ao atendimento especializado na Educação Básica, pelo fato de as SRMs serem equipadas e os professores com certo preparo, buscam sempre completar sua formação;

b) Quanto às dificuldades, ainda existem, sendo necessária a criação de redes de apoio, em especial na área psicológica e da saúde;

c) Um fato que tem dificultado o trabalho com os alunos é que ao apresentarem problemas de aprendizagem em sala de aula regular são considerados deficientes pelas professoras dessas salas, sem mesmo verificarem o laudo médico, ou ficha de acompanhamento do aluno, ou mesmo usarem algum tipo de avaliação pedagógica para se constatar realmente se é questão de defasagem de aprendizagem ou deficiência. Dessa forma, sem uma avaliação adequada, esses alunos passam a frequentar a SRMs;

d) Evidencia-se que importa muito a troca de experiências entre professoras "veteranas" e novatas, com a possibilidade de as "iniciantes" crescerem, tendo como referência inicial a experiência comprovada. 
A formação docente das professoras das SRMs inclui alguns cursos específicos, mas, mesmo não detendo especificidade em todas as deficiências, costumam enfrentar e realizar o AEE. Nas dificuldades e facilidades encontradas no dia a dia, afirmam que o potencial do aluno pode e deve ser estimulado, independente do seu desempenho, mesmo que ainda não tenha sido desenvolvido. Portanto, o fato de uma criança apresentar um resultado intelectual baixo significa que deverá ser estimulada a elevá-lo, por meio de processos educativos complementares e suplementares, podendo até alcançar o nível de uma criança normal, o que vem a coincidir com a afirmativa do psicólogo Vygotsky (1991) de que todo indivíduo, se estimulado, é favorecido quanto ao seu desenvolvimento intelectual.

"Isto ocorre se a criança for estimulada, acontecendo dessas crianças se mostrarem com inteligência normal podendo confundir o professor da sala regular, se o mesmo não verificar o laudo dessa criança" (Fala da professora). Sendo assim, se estimulada, não podemos afirmar ou profetizar qual será seu limite ou "teto" de desenvolvimento intelectual, já que segundo Vygotsky (1998) o conceito de zona do desenvolvimento proximal na instrução procede na análise dos processos internos ("subterrâneos") de desenvolvimento.

A partir dos relatos das professoras, percebemos que deveriam trabalhar em maior parceria, sendo a professora da sala regular condicionada a esclarecer à professora da SRM todo tipo de dificuldade que os alunos com AEE apresentam durante as suas aulas e em quais atividades eles conseguem avançar. É nesse intercâmbio que os alunos com AEE conseguirão avançar mais, e ambas as professoras presenciarão um melhor resultado de seu trabalho.

Assim, para dar suporte a esta parceria, nos encontros de pesquisa, os saberes sobre os principais aspectos referentes à formação de professores no trabalho com crianças com deficiência intelectual, auditiva e deficiência visual ocasionou a todos melhores esclarecimentos sobre esses assuntos, sendo indicadas leituras, pelos professores pesquisadores do NUSI/UNIMONTES, na área da Educação Inclusiva, esclarecendo mais sobre essas deficiências por intermédio dos seguintes autores: Brasil (2006), Lima e Vieira (2006), Smith (2008), dentre outros. Além desses esclarecimentos, estimulamos o debate e a discussão sobre o incremento das funções psicológicas superiores, pela atividade e pelas influências do meio sociocultural, especialmente na deficiência intelectual que pode, portanto, ser modificada por meio de um processo vivenciado pelo aluno.

Ao nos referirmos sobre crianças e adolescentes com deficiência auditiva, as professoras das SRMs afirmam a dificuldade de se conseguir intérprete em Linguagem Brasileira de Sinais - LIBRAS. Consequentemente, o que ocorre, na maioria das vezes, é que essa criança ou adolescente que não domina a LIBRAS fica com pouca comunicação com a família, com a professora da sala de aula regular e com os colegas de sala.

No caso da surdez,

[...] perda total ou parcial, congênita ou adquirida, da capacidade de compreender a fala por intermédio do ouvido. Manifesta-se como surdez: surdez leve/moderada: perda auditiva de até 70 decibéis, que dificulta, mas não impede o indivíduo de se expressar oralmente, bem como de perceber a voz humana, com ou sem a utilização de aparelho auditivo. Surdez severa/profunda: perda auditiva acima de 70 decibéis, que impede o indivíduo de entender, com ou sem aparelho auditivo, a voz humana, bem como adquirir o código da língua oral. (PARÂMETROS CURRICULARES NACIONAIS, 1999 apud LIMA; VIEIRA, 2006, p. 54).

Com base nessa autora, oportunizamos às professoras das SRMs outros saberes necessários que, com certeza, foram de grande proveito frente ao seu trabalho de orientação às famílias.

Mesmo sem saber realmente a LIBRAS, algumas professoras das SRMs conhecem alguns sinais, que utilizam juntamente com a leitura labial e no dia a dia vão tentando se comunicar com a 
criança ou adolescente. Essa forma de se comunicarem torna-se também uma maneira de comunicação com a família, pois estes sinais simples tornam-se signos nas interações das crianças com seus pares e familiares. Com isso, vão criando maior número de sinais e materiais para facilitar a comunicação. Pudemos perceber que as professoras das SRMs são criativas, tanto na comunicação, como também na confecção de materiais necessários para esse tipo de aprendizado em comunicação. Portanto, ao realizarem esse tipo de comunicação com essas crianças, as professoras percebem que as mesmas possuem e apresentam capacidade cognitiva e inteligência consideradas normais, apesar de toda sua limitação auditiva, conforme constatado por elas.

Em se tratando de deficiência visual, as professoras já identificam ser esta como a redução ou perda total da capacidade de ver melhor e após correção ótica. Diante disso, para as professoras das SRMs, a cegueira em ambos os olhos leva o indivíduo a necessitar do Método Braille, como meio de leitura e escrita, a utilizar computadores com o programa JAWS (programa americano para cegos) ou programa DOZ VOX (programa brasileiro para cegos), existindo ainda outros recursos psicopedagógicos, didáticos e equipamentos especiais na educação, porém nem todos acessíveis econômica e financeiramente aos alunos.

Para a visão reduzida, as professoras esclarecem que pedem à família o resultado do exame feito pelo oftalmologista, sendo que o mesmo pode apresentar a acuidade visual entre 6/20 e 6/60, no melhor olho, em correção máxima. Com isso, o indivíduo ainda consegue ler impressão a tinta, desde que sejam ampliadas ou que utilize a lupa. Confirmam que a ausência da visão afeta algumas atividades especificas, sendo a mais limitada a locomoção no espaço físico, o que, em parte, está sendo atendido. Em se tratando de indivíduo cego, as professoras das SRMs afirmam a necessidade de se trabalhar muito a questão da autoestima desse tipo de aluno, que, inserido na educação, requer uma melhor orientação. Esta afirmação coaduna com o posicionamento dos pesquisadores do NUSI e de alguns autores.

Smith (2008, p. 338) identifica a origem ou surgimento dessa baixa autoestima.

Talvez o modo como as crianças cegas são tratadas e as experiências negativas que elas vivenciam com os colegas durante os anos escolares contribuam para as características listadas a seguir, em geral atribuídas às pessoas cegas na literatura de pesquisa: elas, com frequência, são vistas como pessoas de baixa auto-estima e socialmente imaturas, egocêntricas, tímidas, isoladas, passivas, retraídas e dependentes.

Diante da constatação da autora, percebemos a necessidade de se resgatar a autoestima, em que Vygotsky (1995 apud LIMA; VIEIRA, 2006, p. 79) apresenta conclusão, vindo a confirmar que "a deficiência não é só uma insuficiência, uma magnitude negativa, é também um estímulo para a supercompensação". O autor nos direciona para o seguinte: ao resgatar a autoestima, no indivíduo cego, a supercompensação é estimulada, ocasionando o resultado, resultado esse que seria a estruturação da personalidade pela compensação na conquista de uma posição social.

Há também, segundo as professoras das SRMs, algumas deficiências físicas que podem afetar de forma mais acentuada a aparência física da criança ou jovem, ocasionando a baixa autoestima, que poderá requerer intervenção psicológica ou terapêutica. Alguns autores salientam ser essa baixa autoestima oriunda da relação que se estabelece entre o indivíduo e seu meio social. Confirmam que

Neste contexto, atitudes de não aceitação dos grupos sociais e das famílias, muitas vezes levam a pessoa com deficiência a assumir posturas indesejáveis e excludentes como o isolamento (grifo do autor) colaborando, assim, para dificultar a sua inclusão no ambiente escolar. (SILVA; CASTRO; CASTELO BRANCO, 2006, p. 24). 
Diante desse cenário, confirmado por Silva, Castro e Castelo Branco (2006), surge por meio desses autores a reflexão de que o ideal seria a atuação de uma equipe multiprofissional, composta por educadores especializados, médicos, psicólogos, fisioterapeutas, terapeutas e outros, que trabalharão no processo de reabilitação da criança ou jovem com deficiência física. E, mesmo enquanto realiza seu processo de reabilitação, o indivíduo não deve deixar de frequentar a escola. Ao contrário, os educadores e a família deverão estimulá-lo a participar de todas as atividades curriculares, uma vez que o contato com colegas e professores favorece a reabilitação e, paulatinamente, pressupomos, irá ocorrer a inclusão escolar.

Com todas essas reflexões, como resultado de uma ação conjunta, removendo as barreiras arquitetônicas, procurando adaptar o mobiliário, criando materiais didático-pedagógicos adaptados ao aluno e suas necessidades, contribuindo, portanto, para a sua inclusão escolar.

As professoras das SRMs que trabalham com todo tipo de deficiência e que realizam complementação das atividades realizadas nas salas regulares também observam que nas atividades ligadas à aprendizagem é necessário verificar as capacidades de independência e autonomia do sujeito e analisar se ele consegue adaptar-se às demandas da classe regular, desenvolvendo comportamentos como: atenção, percepção, entender ordens e respondê-las ou, ainda, desenvolver atos criativos.

O que já foi evidenciado sobre o atendimento na SRM deixa claro que um dos procedimentos realizados para a coleta de dados desta pesquisa (grupo focal) permite nos direcionar ao entendimento das diferentes percepções e atitudes acerca de um fato, prática, produto ou serviço já conhecido e comprovado, o que vem favorecer um melhor entendimento dentro da assistência ao aluno com NEEs. Um fato, por exemplo, evidenciado sobre um aluno autista: ele se esconde durante o recreio quando percebe muita gente, no entanto, a atitude adotada pela professora é a de respeitar esse comportamento do aluno. Diante desse fato e dessa prática, a professora busca um maior conhecimento nos livros e materiais disponíveis, e, se necessário, auxílio no serviço especializado, para que o resultado seja uma melhor aceitação da criança e sua consequente inclusão no ambiente escolar.

Os componentes dessa pesquisa estão relacionados no quadro abaixo.

Quadro 1 - Institucional

\begin{tabular}{|c|c|c|}
\hline \multicolumn{3}{|c|}{ Coordenador institucional: Cassandra Catarina Gonçalves Mineiro } \\
\hline \multicolumn{3}{|c|}{ Endereço eletrônico: cassandramineiro@hotmail.com } \\
\hline \multicolumn{3}{|c|}{ Unidade Acadêmica: NUSI - Centro de Ciências Humanas - CCH/UNIMONTES } \\
\hline \multicolumn{3}{|c|}{ Link para Curriculum Lattes: http://lattes.cnpq.br/4106901644546972 } \\
\hline Professores Pesquisadores Participantes & Instituição & Função \\
\hline Professor 1 Leonice Vieira de Jesus Paixão & UNIMONTES & Coordenador Adjunto \\
\hline Professor 2 Carlos Alberto Siqueira Alexandre & UNIMONTES & Professor Pesquisador \\
\hline $\begin{array}{l}\text { Professor } 3 \text { Simone Maria Oliveira Azevedo } \\
\text { Rocha }\end{array}$ & UNIMONTES & Professor Pesquisador \\
\hline Professor 4 Isabel Simões Oliveira & UNIMONTES & Professor Pesquisador \\
\hline Professor 5 Eny Silveira Teles & UNIMONTES & Professor Pesquisador \\
\hline $\begin{array}{l}\text { Professoras Educação Básica Participantes } \\
\text { do Projeto }\end{array}$ & Instituição & Função \\
\hline Profa 1 Adriana Ferreira da Silva & Escola Municipal Ruy Lage & Participante Grupos Focais \\
\hline Profa 2 Adriana Meira Fonseca Belém & $\begin{array}{l}\text { Escola Municipal Dominguinhos } \\
\text { Pereira }\end{array}$ & Participante Grupos Focais \\
\hline
\end{tabular}


O REPENSAR SOBRE AS DIFICULDADES | Cassandra Catarina Gonçalves Mineiro

\begin{tabular}{|c|c|c|}
\hline Profa3 Andrea Cilene Gusmão Souza & Escola Municipal Dú Narciso & Participante Grupos Focais \\
\hline Profa 4 Arlete Durães A. Freire & $\begin{array}{l}\text { Escola Municipal Prof. Hamilton } \\
\text { Lopes }\end{array}$ & Participante Grupos Focais \\
\hline Profa 5 Cláudia Aparecida Ferreira Lima & $\begin{array}{l}\text { Escola Municipal Dominguinhos } \\
\text { Pereira }\end{array}$ & Participante Grupos Focais \\
\hline Profa 6 Débora Cássia Santos Caribé & $\begin{array}{l}\text { Escola Municipal Celestino Pereira } \\
\text { Salgado }\end{array}$ & Participante Grupos Focais \\
\hline Profa 7 Edna Marlúcia Soares Maia & Escola Municipal Afonso Salgado & Participante Grupos Focais \\
\hline Profa 8 Edy Maura Figueiredo Fernandes & Escola Municipal Alcides Carvalho & Participante Grupos Focais \\
\hline Profa 9 Eunice Alves da Silva & \begin{tabular}{|l|} 
Escola Municipal João Valle \\
Maurício \\
\end{tabular} & Participante Grupos Focais \\
\hline Profa 10 Edite de Jesus Pereira da Silva & $\begin{array}{l}\text { Secretaria Municipal Educação - } \\
\text { SME Seção Ed. Inclusiva } \\
\end{array}$ & Participante Grupos Focais \\
\hline Profa 11 Eleni Dias Alves Fernandes & $\begin{array}{l}\text { Escola Municipal Hilda Carvalho } \\
\text { Mendes }\end{array}$ & Participante Grupos Focais \\
\hline Profa 12 Flávia Fabiane F. Senário & $\begin{array}{l}\text { Escola Municipal Egídio Cordeiro } \\
\text { Aquino }\end{array}$ & Participante Grupos Focais \\
\hline Profa 13 lara Lopes Duarte Figueiredo & $\begin{array}{l}\text { Escola Municipal Prof }{ }^{\mathrm{a}} \text { Hilda Car- } \\
\text { valho Mendes }\end{array}$ & Participante Grupos Focais \\
\hline Profa 14 Kátia Liliany Oliveira Macedo & SME- Seção Ed. Inclusiva & Participante Grupos Focais \\
\hline Profa 15 Ladir Bertoldo da Silva & E. M. Prof ${ }^{a}$ Hilda Carvalho Mendes & Participante Grupos Focais \\
\hline Profa 16 Leilah Cardoso Costa & E. M. José Joaquim de Azevedo & Participante Grupos Focais \\
\hline Profa 17 Luciana Gomes Rocha e Prates & E. M. João Vale Maurício & Participante Grupos Focais \\
\hline Profa 18 Luciene de Fátima S. Aragão Ramos & E. M. Dr. João Alves & Participante Grupos Focais \\
\hline Profa 19 Luciene Pimenta Borges & E. M. Zizinha Ribeiro & Participante Grupos Focais \\
\hline Profa 20 Maria Aparecida Alves Durães & E. M. Mestra Fininha & Participante Grupos Focais \\
\hline Profa 21 Maria Aparecida Maia Chelone Aleixo & E. M. Jason Caetano & Participante Grupos Focais \\
\hline Profa 22 Maria Cleusa Rodrigues Soares & SME-Seção Ed. Inclusiva & Participante Grupos Focais \\
\hline 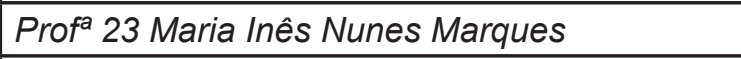 & E. M. D ${ }^{\text {a Vidinha Pires }}$ & Participante Grupos Focais \\
\hline Profa 24 Maria Janete Oliveira Macedo & SME-Seção Ed. Inclusiva & Participante Grupos Focais \\
\hline Profa 25 Maria Jose Gomes Andrade & E. M. Afonso Salgado & Participante Grupos Focais \\
\hline Profa 26 Maria de Lourdes Gomes Lima & E. M. José Joaquim de Azevedo & Participante Grupos Focais \\
\hline Profa 27 Patrícia Santana da Silva & E. M. Da Vidinha Pires & Participante Grupos Focais \\
\hline Profa 28 Rosangela Gomes Fagundes & E. M. Jair de Oliveira & Participante Grupos Focais \\
\hline Profa 29 Rosangela Gomes Soares & E. M. Prof ${ }^{a} M^{a}$ Lourdes Pinheiro & Participante Grupos Focais \\
\hline Profa 30 Simone Souza Fonseca & E. M. Jason Caetano II & Participante Grupos Focais \\
\hline Profa 31 Vanessa Rodrigues Ribeiro & $\begin{array}{l}\text { Escola Estadual Beato José de } \\
\text { Anchieta }\end{array}$ & Participante Grupos Focais \\
\hline Profa 32 Celma Mendes Maia & $\begin{array}{l}\text { Escola Estadual Beato José de } \\
\text { Anchieta }\end{array}$ & Participante Grupos Focais \\
\hline Profa 33 Anna Angélica de Castro Souza & Escola Estadual Doutor João Alves & Participante Grupos Focais \\
\hline Profa 34 Glaucilene Alves Barbosa & Escola Estadual Doutor João Alves & Participante Grupos Focais \\
\hline Profa 35 Helenice Ferreira da Silva & Escola Estadual Francisco Peres & Participante Grupos Focais \\
\hline Profa 36 Marcia Aparecida Cardoso de Oliveira & Escola Estadual Francisco Peres & Participante Grupos Focais \\
\hline Profa 37 Maria de Fátima Cordeiro & $\begin{array}{l}\text { Escola Estadual Dona Quita } \\
\text { Pereira }\end{array}$ & Participante Grupos Focais \\
\hline
\end{tabular}




\begin{tabular}{|l|l|l|}
\hline Prof $^{a} 38$ Noelina Pereira Soares & $\begin{array}{l}\text { Escola Estadual Levi Durães } \\
\text { Peres }\end{array}$ & Participante Grupos Focais \\
\hline Prof $^{a} 39$ Vera Lúcia Fróes Alves & $\begin{array}{l}\text { Escola Estadual Prof }{ }^{a} \text { Helena } \\
\text { Prates }\end{array}$ & Participante Grupos Focais \\
\hline Prof $^{a} 40$ Claudemira Soares Pereira & $\begin{array}{l}\text { Escola Estadual Levi Durães } \\
\text { Peres }\end{array}$ & Participante Grupos Focais \\
\hline
\end{tabular}

Fonte: Pesquisa realizada pelos professores da UNIMONTES em 2010.

\subsection{Organização do currículo na educação básica com abrangência no AEE}

Em relação às atividades curriculares, ficou evidente pela fala das professoras das SRMs que na sala de aula regular o currículo desenvolvido na Educação Básica permanece o mesmo, para todos os alunos, não havendo diferenciação para aquele aluno que necessita do AEE. Ocorre que esse tipo de aluno considerado "deficiente" realiza as atividades dentro das suas capacidades e limites, apresentando-se mais vagaroso e com certa dificuldade em realizar todas as atividades. Dependendo do tipo de deficiência, ele poderá ter um professor de apoio, que irá acompanhá-lo durante todo o período de aula, conforme direito prescrito na legislação e embasado no diagnóstico realizado pela equipe de profissionais credenciados (médico, terapeuta, fonoaudiólogo, psicólogo e outros). Caso contrário, não terá esse direito.

Questionamos às professoras sobre os níveis de deficiência mental desses alunos com NEEs, ou das altas habilidades, o que nos proporcionou uma discussão sobre inteligência. Afinal, o que é inteligência? Seria um traço ou atributo apreendido que alguns têm em demasia e que falta em outros? Isto nos levou a buscar na Psicologia um embasamento teórico mais consistente, sendo que encontramos diversos estudos comparativos interculturais demonstrando a influência da escolarização no aprendizado que propicia o desenvolvimento da inteligência e, mais precisamente, nos resultados alcançados dentro da própria escola.

Segundo Piaget (1977), o sujeito e o meio são elementos interatuantes na construção da inteligência, que se desenvolve conforme estágios universais. Em Vygotsky (1991), as formas de desenvolvimento das funções mentais e da inteligência podem variar de acordo com a cultura e as particularidades dos sujeitos. Para ele, a deficiência mental leve se alarga ou se estreita, dentro da faixa na qual se encontra, de acordo com o tipo de apoio demandado pelo sujeito: pode ser amplo, intermitente e permanente, o que direciona não se conceber a inteligência como algo imutável. Nessa possibilidade, de a inteligência ser potencializada, amplia-se muito o seu significado por intermédio do conceito de Zona de Desenvolvimento Proximal, definido por Vygotsky (1998), na abordagem da deficiência mental que, ao ser estimulada, implica a possibilidade de criação de novos potenciais. Conceber o desenvolvimento da inteligência desta forma maximiza o papel das mediações ou intervenções. Portanto, a deficiência mental pode ser modificada através de processo vivenciado pelo indivíduo, em que seu potencial tem a possibilidade ou não de ser estimulado e desenvolvido. Logo, uma criança, ao apresentar resultado intelectual baixo na escola, deverá ser estimulada a elevá-lo por meio de processos psicopedagógicos, mediante os quais poderá se aproximar ou alcançar o nível de uma criança normal. Sendo assim, não se deve afirmar ou profetizar qual será seu limite de desenvolvimento cognitivo.

Segundo Lima e Vieira (2006), além da capacidade cognitiva ligada à aprendizagem, é necessário verificar também as capacidades de autonomia e independência do indivíduo, e observar se ele consegue adaptar-se às demandas da classe regular. Em especial, o quadro denominado leve deficiência mental deverá ser avaliado, por ocorrer, muitas vezes, num contingente 
em que a maioria dos indivíduos diagnosticados com esse tipo de deficiência é geralmente de crianças pouco estimuladas, com pouca escolarização e de famílias das camadas populares e socioeconomicamente menos favorecidas e que podem ser confundidas. Outro grupo menor, chamado deficiência mental profunda, apresenta-se conjugado a alterações genéticas, doenças hereditárias, como também lesões cerebrais identificáveis. É o caso da síndrome de Down (que pode se apresentar leve, moderada ou profunda) e outras lesões cerebrais que são originárias de diferentes fontes e etiologias, decorrentes de doenças da mãe ou da própria criança (LIMA; VIEIRA, 2006). Contudo, isso não significa que a criança não consiga aprender, o que nos direciona a afirmar, pela prática evidenciada, e confirmada pelos autores, haver sim alguma aprendizagem, diante do tipo de estimulação utilizada.

\subsubsection{Organização das atividades da educação básica realizadas nas SRMs}

As atividades da Educação Básica se compõem das atividades relacionadas e trabalhadas nas salas regulares, e que são em sua maioria atividades relacionadas aos conteúdos de Português e Matemática, indicadas também a serem trabalhadas nas SRMs, com encaminhamento das dificuldades pela professora da sala regular, oferecendo assim suporte na aprendizagem das crianças com NEEs.

Ao iniciarem as atividades da Educação Básica nas SRMs, as professoras que trabalham nessas salas recebem o aluno, a família dele e o diagnóstico, ou seja, o Laudo Médico que acompanha a criança ou jovem. Em muitos casos, os alunos não possuem ainda o Laudo Médico, pelo fato de este não ter ficado pronto e, em outros casos, a família não consegue o Laudo devido a muitas exigências com os exames, ou ainda, por omissão de algumas famílias (fala das professoras). As professoras ressaltaram que, devido à existência de poucos médicos, psicólogos, fonoaudiólogo, dentre outros profissionais dessa área, e devido à falta de interesse da família em levar os filhos à consulta, muitas vezes elas iniciam o trabalho com o aluno na sala de recurso somente com a anamnese e o relatório do aluno fornecido pela família, entendendo que os familiares providenciarão o laudo.

Antes de trabalhar as atividades, cada professora da SRM recebe a criança de maneira afetuosa e proporcionando a ela segurança dentro do novo ambiente. Em seguida, verifica com a professora da sala regular quais dificuldades essa criança ou jovem apresenta e/ou verifica através de ficha pedagógica que a acompanha. Geralmente, no conteúdo de Português apresentam dificuldades na área de leitura e escrita, e em Matemática, nas operações.

Para melhor esclarecermos sobre as atividades de Português a serem realizadas pelas professoras das SRMs, tomamos como necessário apresentar logo abaixo, no Quadro Demonstrativo I, em que vamos exemplificar, apenas com uma amostragem das escolas estaduais, pesquisadas como referência para essa modalidade pedagógica. Verificamos que o número de alunos que necessitam receber o atendimento educacional especializado - AEE é bastante superior ao número dos demais alunos em processo de alfabetização, porém esses alunos com AEE não são todos atendidos, sendo as crianças e jovens sem laudo deixados de lado, pois não é exigido da professora da sala regular assistência a essas crianças. Exemplo: Escola A são 35 alunos com NEEs e somente 15 são atendidos, pelo fato de apresentarem o Laudo Médico. O mesmo ocorre nas demais escolas. Portanto, verificamos que é cobrado das professoras o avanço das crianças e jovens com laudo, e elas deverão apresentar um relatório que satisfaça esse tipo de exigência.

A idade dos alunos do AEE também é muito variável, na qual percebemos uma mistura de crianças com jovens e adultos, uma vez que na Educação Básica eles têm direito de permanecer na escola dois anos a mais. Há também os casos de alunos que saem da escola, podendo retornar 
depois e, conforme a idade com que retornam, eles deverão frequentar a Educação de Jovens e Adultos - EJA, no turno noturno, porém, devido à sua condição mental apresentando comportamento mais infantilizado, muitos ainda conseguem frequentar durante o dia, porque a frequência noturna torna-se perigosa para eles.

Diante das atividades de leitura, no Quadro Demonstrativo 1, na coluna onde se encontram alunos com Laudo e em processo de Alfabetização, a maioria dos alunos consegue ler silabando, o que não significa que têm uma leitura correta, um ou outro identifica palavras e apenas um aluno pertencente à escola A sabe ler corretamente. Em se tratando da escrita, em todas as escolas, todos eles sabem copiar olhando para a escrita, porém, consideramos 24 alunos que escrevem o nome sem olhar, copiam e já realizam alguma separação em sílabas, sendo raro o pré-silábico, que ocorre somente na escola $B$, num total de 24 alunos assistidos, com laudo, de um total de 32, ficando 8 alunos com NEEs sem atendimento. Num total de 184 alunos com NEEs, apenas 117 são assistidos, ficando 67 alunos sem laudo e sem assistência efetiva, mas que continuam frequentes à escola.

Quadro 2 - Demonstrativo I - Português: leitura e escrita no ensino fundamental.

\begin{tabular}{|c|c|c|c|c|}
\hline Escola & $\mathrm{N}^{\circ}$ de alunos $\mathrm{AEE}$ & $\begin{array}{c}N^{\circ} \text { de alunos com } \\
\text { Laudo em processo } \\
\text { alfabetização }\end{array}$ & $\begin{array}{l}\text { Leitura dos alunos } \\
\text { do AEE }\end{array}$ & Níveis de Escrita \\
\hline Escola A & 35 & 15 & Lêem silabando & Escrevem copiando \\
\hline Escola B & 32 & 24 & Lêem silabando & $\begin{array}{c}\text { Escrevem o nome } \\
\text { sem olhar, estágio } \\
\text { pré-silábico. }^{2}\end{array}$ \\
\hline Escola C & 44 & 44 & Lêem silabando & Escrevem copiando \\
\hline Escola D & 28 & 05 & Lêem silabando & Escrevem copiando \\
\hline Escola E & 15 & 15 & Lêem silabando & Escrevem copiando \\
\hline Escola F & 30 & 14 & Lêem silabando & Escrevem copiando \\
\hline Total & 184 & 117 & - & - \\
\hline
\end{tabular}

Fonte: Pesquisa com as professoras das Escolas Estaduais, do município de Montes Claros - 2013

Os avanços são demorados, no entanto são registrados em relatório pelas professoras das SRMs, e, a qualquer conquista da criança, a família procura a professora da SRMs para agradecer, demonstrando-se felizes com o pequeno avanço do aluno.

O Quadro Demonstrativo 2 (abaixo) evidencia as dificuldades dos alunos do AEE com relação às operações matemáticas. Num total de 117 alunos - de todas as Escolas, alunos com NEEs e com laudos - são assistidos e conseguem realizar as duas operações utilizando-se do material concreto. Contudo, na escola $\mathrm{C}$, dos 44 alunos assistidos e com laudo, somente 30 realizam as operações com material concreto, os outros 14 não precisam do material, pois realizam as operações fundamentais de maneira abstrata. No entanto, observamos que a maioria dos alunos com NEEs não conseguem fazer leitura matemática, apenas os 14 alunos da escola $\mathrm{C}$. A quantidade de alunos que não são assistidos corresponde a mesma, ou seja, 67 alunos com NEEs, sem laudo.

Também foi questionado sobre adições com reserva, ou subtrações, sendo que as professoras afirmaram que nenhum deles não conseguiu realizar, e torna-se difícil para elas pressupor se irão conseguir.

\footnotetext{
${ }^{1}$ Essas Nível Pré-silábico - não se busca correspondência com o som; as hipóteses das crianças são estabelecidas em torno do tipo e da quantidade de grafismo. (FERREIRO, 2013).
} 
Quadro 3 - Demonstrativo II - Matemática: adição e subtração no ensino fundamental.

\begin{tabular}{|c|c|c|c|c|}
\hline Escolas & $\mathbf{N}^{\mathbf{0}}$ de alunos AEE & $\begin{array}{c}\mathbf{N}^{\mathbf{0}} \text { Alunos que } \\
\text { realizam as duas } \\
\text { operações }\end{array}$ & $\begin{array}{c}\text { Idade dos alunos do } \\
\text { AEE }\end{array}$ & $\begin{array}{c}\text { Utilizam material } \\
\text { concreto nas } \\
\text { operações }\end{array}$ \\
\hline Escola A & 35 & 15 & 11 e 12 anos & $\begin{array}{c}\text { Sim, porém não fazem } \\
\text { leitura matemática. }\end{array}$ \\
\hline Escola B & 32 & 24 & 10 a 12 anos & $\begin{array}{c}\text { Sim, porém não fazem } \\
\text { leitura matemática. }\end{array}$ \\
\hline Escola C & 44 & 44 & 4 a 40 anos & $\begin{array}{c}\text { Só } 30 \text { alunos utilizam } \\
\text { material concreto }\end{array}$ \\
\hline Escola D & 28 & 05 & 08 a 12 anos & $\begin{array}{c}\text { Sim, porém não fazem } \\
\text { leitura matemática. }\end{array}$ \\
\hline Escola E & 15 & 15 & 08 a 12 anos & $\begin{array}{c}\text { Sim, porém não fazem } \\
\text { leitura matemática. }\end{array}$ \\
\hline Escola F & 30 & 14 & 08 a 16 anos & $\begin{array}{c}\text { Sim, porém não fazem } \\
\text { leitura matemática. }\end{array}$ \\
\hline Total & 184 & 117 & - & - \\
\hline
\end{tabular}

Fonte: Pesquisa com as professoras das Escolas Estaduais do município de Montes Claros - 2013.

Outra informação colhida das professoras se refere à avaliação desses estudantes com AEE. Segundo as docentes, eles são encaminhados à professora da sala regular, ressaltando que elas, das SRMs, não participam das avaliações, o que consideram haver diante disso uma situação de intervenção educacional.

Mesmo sem participar da avaliação, o professor da sala de recurso também faz a sua avaliação no espaço de seu atendimento e, após avaliar, realiza entrevista com a família do aluno, buscando informar o resultado da avaliação para que a família possa, caso necessite, agendar consultas e essa criança possa receber acompanhamento médico e/ou profissional adequado. Essa entrevista, além de ser realizada pelo professor da sala de recurso, é feita também pelo supervisor da escola. Após essa avaliação ser encaminhada à professora da sala regular, é solicitado a ela o preenchimento do relatório do aluno.

Ao falarmos sobre avaliação, o foco assentou-se no seguinte questionamento: "Como unificar o processo de avaliação a essas diferentes categorias, para que seja o mesmo nas escolas?" Surgiu então a ideia de se criar uma avaliação para o acompanhamento do dia a dia, mediante Plano de Atendimento Educacional Especializado (PAEE), criado com mais especificidade pelas professoras da rede Estadual, que unificaram esse tipo de acompanhamento a todas as escolas locais e regionais.

\section{3 | RESULTADOS OBTIDOS E DISCUSSÃO REALIZADA}

Iniciamos as discussões com os eixos temáticos Formação de Professores para inclusão escolar, paralelamente com o eixo de atendimento educacional especializado nas salas de recursos multifuncionais, em que se constatou a necessidade de se conhecer e discutir sobre as legislações mais recentes, ou seja, os Decretos $n^{\circ} 7.611$ e 7.612, de 17 de novembro de 2011, que dispõem sobre a Educação Especial, o atendimento educacional especializado e o Plano Nacional dos Direitos da Pessoa com Deficiência. Como resultado, obtivemos fundamento específico direcionado ao conhecimento legal dos direitos das crianças e jovens com NEEs. Consideramos pertinente conhecer essas e outras novas leis que irão surgindo. 
As expectativas das professoras com relação a esta pesquisa é que esse espaço permitiu-lhes discutir sobre a legislação, as dificuldades enfrentadas no trabalho, as questões referentes às redes de apoio local, ocasionando um redirecionamento, em saber a quem recorrer, em relação às várias dificuldades enfrentadas pelas professoras nas SRMs. Sem deixar de mencionar que a troca de experiências entre professoras "veteranas" e professoras "iniciantes" acrescentou muito ao trabalho que vêm desenvolvendo nessas salas. Essa troca significativa de experiências possibilitou como resultado, ainda, atualização de materiais criados e confeccionados para as SRMs, procedimentos, conceitos e maior segurança em poder atuar nessas salas.

Salientamos também a palestra do professor e psicólogo citado anteriormente, que ocasionou às professoras sobre como lidar com o aluno de AEE, em especial com TEA e TDO, mediante discussão que sanou várias dúvidas relacionadas à questão: "Como se deve realizar as atividades com esse tipo aluno?". O resultado direcionou-lhes a uma maior segurança em se trabalhar com esses tipos de alunos, ficando como sugestão o estudo e a pesquisa dentro da teoria psicológica do comportamento de Skinner, que segundo Coutinho e Moreira (2004, p. 26), "Para os behavioristas, o objeto de estudo da Psicologia é o comportamento ou as reações observáveis de um organismo pelas respostas a estímulos do meio ambiente, também observáveis", o que vem a coincidir com Teixeira (2014), que mostra, em seu trabalho, as técnicas comportamentais de Skinner como um dos meios de lidarmos com as crianças com TEA ou TDO. Para Teixeira (2014) as técnicas comportamentais de Skinner foram repetidas, experimentadas e utilizadas até hoje com muito sucesso em todo o mundo. "Estudos publicados nos Estados Unidos e em países da Europa mostram que há uma redução entre 50\% e 90\% dos problemas comportamentais infantis relacionados com indisciplina, desafio e oposição às regras [...]" (TEIXEIRA, 2014, p. 66), que de acordo com o autor essas intervenções foram muito eficientes para auxiliar na melhoria do comportamento.

Mesmo afirmando no início desse trabalho sobre a idéia de condicionamento (do não precisa pensar, nem perguntar para que, do fazer), com a mudança de paradigma a toda Educação em geral e a Educação Inclusiva, somos voltados a perceber a necessidade, em determinados casos, de usarmos as técnicas de comportamento de Skinner, como uma das formas de conseguirmos algum resultado na adequação comportamental da criança com TEA e TDO.

Todo tipo de discussão realizada conduziu às participantes realizarem reflexões, reverem o seu trabalho, para melhor direcionarem as modificações necessárias dentro das suas necessidades mais urgentes, uma vez que muitas dessas experiências repensadas auxiliarão como instrumento de inclusão na escola.

\section{4 | CONSIDERAÇÕES FINAIS}

Os resultados obtidos na realização desta pesquisa no Município de Montes Claros/MG nos conduziram a perceber a necessidade de ressaltar que a maioria dos professores das SRMs são capazes de enfrentar e superar os obstáculos apresentados em sua formação, mobilizando-se por meio da reflexão crítica e psicológica acerca dos mesmos. Percebemos, no entanto, que os dados coletados na pesquisa ainda não identificam claramente as ações direcionadas para a capacitação específica dos professores das salas regulares da Educação Básica, porém, torna-se incisivo que os mesmos deveriam atuar com mais parceria junto às professoras das SRMs e, com isso, proporcionar maior inclusão a ser realizada tanto nas SRMs, como nas salas regulares.

As maiores dificuldades enfrentadas se referem à criação de redes de apoio, principalmente na área da saúde, quando o aluno fica a espera do laudo quase um ano, ou mais, não podendo ainda 
ser direcionado ao atendimento especial. Entretanto, as professoras das SRMs recebem o aluno assim mesmo, por entenderem a necessidade do mesmo e da sua família. A situação na qual vivemos requer uma continuidade de políticas específicas de educação especial, inseridas na consolidação e reestruturação do sistema de ensino, como: a reutilização dos estudos na área da psicologia, como suporte teórico ao lidar com as diversas deficiências; um diagnóstico mais acessível para as crianças com AEE; Plano de Atendimento Educacional Especializado (PAEE), criado pelas professoras da rede Estadual, para acompanhamento a todas as escolas locais e regionais, favorecendo assim um processo unificado de avaliação; garantia de oferta da capacitação na formação docente; e maior envolvimento dos demais componentes da comunidade escolar, parceria da escola com a família são alguns dos elementos fundamentais para que a educação seja realmente inclusiva.

Assim, nos Encontros de Pesquisa realizados na UNIMONTES, evidenciamos a preocupação das professoras das SRMs em: estimular sempre as crianças e jovens do AEE; enfrentar qualquer tipo de deficiência, mesmo não possuindo curso específico, procurando sempre pesquisar e estudar para maior segurança; buscar, quando necessário, os profissionais da área da saúde e os que atuam nas especificidades do AEE; e utilizar da psicologia como suporte às dificuldades diárias e instrumento de inclusão escolar. 


\section{Referências}

BRASIL. Decreto n 7.611, de 17 de novembro de 2011. Dispõe sobre a educação especial, o atendimento educacional especializado e dá outras providências. Diário Oficial da União, Brasília, DF, 18 nov. 2011a.

Decreto $n^{\circ}$ 7.612, de 17 de novembro de 2011. Institui o Plano Nacional dos Direitos da Pessoa com Deficiência - Plano Viver sem Limite. Diário Oficial da União, Brasília, DF, 18 nov. 2011b.

Ministério da Educação. Secretaria de Educação Especial. Manual de Orientação: Programa de Implantação de Sala de Recursos Multifuncionais. Brasília, DF: MEC; SEESP, 2010. Disponível em: $\quad<$ http://especialdeadamantina.files.wordpress. com/2012/11/manual-de-orientac3a7c3a3o-implantac3a7c3a3o-de-salas-multifuncionais.pdf.>. Acesso em: 10 set. 2014.

Ministério da Educação. Secretaria de Educação Especial. Política Nacional de Educação Especial na Perspectiva da Educação Inclusiva. Brasília, DF: MEC; SEESP, 2008.

Ministério da Educação. Secretaria de Educação Especial. Sala de Recursos Multifuncionais: Espaço para Atendimento Educacional Especializado. Brasília, DF: MEC/SEESP, 2006. Disponível em: <http:// www.dominiopublico.gov.br/download/texto/me002991. pdf.>. Acesso em: 6 set. 2015.

Secretaria de Direitos Humanos da Presidência da República. Secretaria Nacional de Promoção dos Direitos da Pessoa com Deficiência. Viver Sem Limite: Plano Nacional dos Direitos da Pessoa com Deficiência. Brasília, DF: SDH-PR/SNPD, 2013. Disponível em: <http://www.desenvolvimentosocial.sp.gov.br/a2sitebox/ arquivos/documentos/633.pdf>. Acessso em: 20 set. 2014.

Secretaria Especial dos Direitos Humanos. Coordenadoria Nacional para Integração da Pessoa Portadora de Deficiência. Convenção sobre os Direitos das Pessoas com Deficiência. Brasília, DF: SEDP; CORDE, 2007. Disponível em: <http://portal.mec. gov.br/index.php?option=com_docman\&view=download\&alias $=424$-cartilha-c\&category slug=documentos-pdf\&Itemid=30192>. Acesso em: 4 ago. 2015.
CARVALHO, M. B. W. B. Professores de educação especial. In: SILVA. M. G.; CARVALHO, M. B. W. B. (Org.). Faces da inclusão. São Luis: Edufma, 2010.

COUTINHO, M. T. C.; MOREIRA, M. Psicologia da educação: um estudo dos processos psicológicos de desenvolvimento e aprendizagem humanos, voltado para a educação: ênfase nas abordagens interacionistas do psiquismo humano. 10. ed. Belo Horizonte: Formato Editorial, 2004.

FERREIRO, E. Níveis estruturais da linguagem escrita, segundo Emília Ferreiro. Pedagogia ao Pé da Letra, abr. 2013. Disponível em: <http://pedagogiaaopedaletra. com/niveis-estruturais-da-linguagem-escrita-segundo-emilia-ferreiro>. Acesso em: 3 mar. 2016.

LIMA, P. A.; VIEIRA, T. Educação inclusiva e igualdade social. São Paulo: Avercamp, 2006.

ORGANIZAÇÃO MUNDIAL DA SAÚDE. Relatório mundial sobre deficiência. 2011. Disponível em: <http://www. pessoacomdeficiencia.sp.gov.br/usr/share/documents/ RELATORIO_MUNDIAL_COMPLETO.pdf>. Acesso em: 8 ago. 2014 .

PIAGET, J. O desenvolvimento do pensamento: equilibração das estruturas cognitivas. Tradução Álvaro Figueiredo. Lisboa: Publicações Dom Quixote, 1977.

SILVA, A. F.; CASTRO, A. L. B.; CASTELO BRANCO, M. C. M. A inclusão escolar de alunos com necessidades educacionais especiais: deficiência física. Brasília, DF: MEC/SEESP, 2006. 67 p.

SMITH, D. D. Introdução à educação especial: ensinar em tempos de inclusão. Tradução Sandra Moreira de Carvalho. 5. ed. Porto Alegre: Artmed, 2008. 480 p.

TEIXEIRA, G. O reizinho da casa. 2. ed. Rio de Janeiro: Best Seller Ltda, 2014.

VYGOTSKY, L. S. Pensamento e linguagem. São Paulo: Martins Fontes, 1991.

. A formação social da mente. São Paulo: Martins Fontes, 1998. 